\title{
Research on the nanolevel influence of surfactants on structure formation of the hydrated Portland cement compositions
}

\author{
Alexander Guryanov ${ }^{1, *}$, Sofya Korenkova $^{1}$, and Yulia Sidorenko ${ }^{1}$ \\ ${ }^{1}$ Samara State Technical University, Institute of Architecture and Civil Engineering, \\ Molodogvardeyskaya str. 194, 443001 Samara, Russia
}

\begin{abstract}
The research of the structure formation process on a nanolevel of the samples of hydrated Portland cement compositions containing the modifying additives has been conducted with the help of small angle neutron scattering method. Carbonate and aluminum alkaline slimes as well as the complex additives containing surfactants were used as additives. The influence of slimes and surfactants on structural parameters change of Portland cement compositions of the average size of the disseminating objects, fractal dimension samples is considered. These Portland cement compositions are shown to be fractal clusters.
\end{abstract}

\section{Introduction}

There is a formation of particles of calcium silicate hydrate (C-S-H) in the course of hydration of cement clinker. Complex gel framework of C-S-H particles is formed as a result of cement stone formation. Structural parameters of particles C-S-H and the cement matrix itself change when shifting from nanolevel to micro level in accordance with the sizes of the formed cement particles. The structural parameters also affect the properties of the formed cement stone. Firmness, durability, water resistance, frost resistance and other properties of cement stone depend on nanoparticles $\mathrm{C}-\mathrm{S}-\mathrm{H}$ form and sizes distribution, a ratio of free water and water filling the space between firm hydro silicates particles as well as pores and their form and size distribution are thus determined by structural parameters of material on micro and a nanolevel.

To create cement compositions with the particular set properties various additives (fillers, modifiers) having both artificial (e.g. carbon materials) and technogenic (slimes) origin $[1,2]$ are used. The applied additives influence the structure of initial materials and their operational properties [3-8]. It is particularly observed in the presence of nanodisperse component of the additives in cement compositions $[9,10]$.

The utilization of mineral slimes is a great problem for industrial enterprises. At the same time chemical composition stability and high dispersion allow to use them as additives in cement compositions.

\footnotetext{
* Corresponding author: gurjanovam@mail.ru
} 
This paper presents the research of the structure formation process on a nanolevel of samples of the hydrated Portland cement compositions modified by additives of technogenic origin. The research has been conducted with the help of small angle neutron scattering method. Structural parameters of Portland cement compositions are determined. Surfactants influence on structural parameters is also considered in this paper.

\section{Materials}

Slimes are formed as a result of chemical reaction processes, dispersion and adsorption, as well as hashing, upholding and firm particles coagulation of oversaturated sewage solution in purification or water softening in industrial enterprises of metal working, oil processing, thermal power plants. Slimes are the suspension characterized by structure stability, composition homogeneity and composition constituency [11]. Slime formation conditions are as follows: sol-gel technology and content of nanodisperse component allowing to compare them to nanotechnogenic raw materials $[9,10]$.

In this work slimes which can be referred to as filling ones (carbonate slimes) or structure-forming (aluminum alkaline slimes) by targeting action were used as additives in the Portland cement compositions. Slimes were purified at the final stage of their formation. The chemical composition of slimes depends mainly on the type of formation engineering procedure and conditions [11]. Slimes composition used in this work is given in table 1.

Table 1. Mineral composition of slimes.

\begin{tabular}{|c|c|c|c|c|c|c|c|}
\hline Slime sample & $\begin{array}{c}\mathbf{A l}_{\mathbf{2}} \mathbf{O}_{\mathbf{3}} \\
{[\%]}\end{array}$ & $\begin{array}{c}\mathbf{C a O} \\
{[\%]}\end{array}$ & $\begin{array}{c}\mathbf{M g O} \\
{[\%]}\end{array}$ & $\begin{array}{c}\mathbf{F e}_{2} \mathbf{O}_{3} \\
{[\%]}\end{array}$ & $\begin{array}{c}\mathbf{S i O}_{2} \\
{[\%]}\end{array}$ & $\begin{array}{c}\mathbf{S O}_{3} \\
{[\%]}\end{array}$ & $\begin{array}{c}\text { Losses in case } \\
\text { of steaming } \\
{[\%]}\end{array}$ \\
\hline Carbonate & $0-13$ & $36-47$ & $2-14$ & $2-13$ & $2-4$ & $0-6$ & $34-41$ \\
\hline $\begin{array}{c}\text { Aluminum } \\
\text { alkaline }\end{array}$ & $43-59$ & $0-9$ & $0-4$ & $0-7$ & $0-1$ & $0-8$ & $32-57$ \\
\hline
\end{tabular}

Cement compositions samples were made on the basis of non additive Portland cement. In case of Portland cement hydration carbonate or aluminium alkaline slimes were added in quantity of $3-5 \%$. The water cement ratio ranged from 0.27 to 0.30 . When adding surfactants the water cement ratio decreased to 0.20 .

\section{Research Methods}

Structural parameters of Portland cement compositions samples were defined with the help of the small angle neutron scattering method (SANS) [12] allowing to examine over atom structure of substance within the distances from 1 nanometer to 100 nanometers. SANS intensity is defined by dispersing ability of non-uniformity and contrast on section phases boundaries allowing to study nano objects of different physical nature and aggregate state.

Dispersion by disperse systems is isotropic and SANS intensity $I(q)$ depends only on the transferred neutron impulse

$$
q=(4 \pi / \lambda) \sin (\theta / 2)
$$

where $\theta$ - scattering angle. For monodisperse systems SANS intensity is proportional to intensity of one particle dispersion averaged in all directions and bears in itself information about over atom structure of dispersing particle. The experiment results processing concerning SANS is implemented by means of the program complex ATSAS 2.1 [13].

Small angle neutron scattering intensity of by ensemble of particles or non-uniformity can be presented in the form [12] 


$$
I(q) \sim P(q) S(q),
$$

where $P(q)$ and $S(q)$ - a shape factor and a structural factor of a particle, respectively. In case of execution of a condition of $q R_{c}<1$ (Guinier regime) a structural factor of $S(q)=1$. In this case intensity of small angle neutron scattering is defined by the characteristic size of particles $R_{c}$ and shape factor of $P(q)$, that is the form of dispersing particles or nonuniformity:

$$
I(q) \sim I(0) \exp \left[-\left(q R_{g}\right)^{2} / 3\right]
$$

From data on small angle neutron scattering intensity in Guinier regime it is possible to evaluate the radius of a gyration of $R_{g}$ of particles and their characteristic size $R_{c}$.

There is (Porod regime), degree dependence intensity of dispersion on the transferred impulse providing $q R_{c}>1$ :

$$
I(q) \sim q^{-n}
$$

From the degree index deviation $n$ from Porod asymptotic $(n=4)$ it is possible to determine fractal dimensionality. In case of volume or mass fractals the index $n$ corresponds to fractal dimensionality of $D_{V}$ where $1<D_{V}<3$. Providing the dispersion by objects with fractal surfaces the index $n$ is within the interval $3<n=6-D_{S}<4$, where $D_{S}$ fractal surface dimensionality and $2<D_{S}<3$.

Thus, it is possible to determine fractal type by an inclination of straight sections of SANS dependences constructed in double logarithmic scale (volume or surface) and value of fractal dimensionality.

\section{Results}

Ranges of SANS intensity were measured in Petersburg Nuclear Physics Institute on the diffractometer "Membrana-2" set on the WWR-M reactor [14-16]. Neutron wavelength was $\lambda=0.3$ nanometers, line width was $\Delta \lambda \lambda=0.3$. The range of the registered transferred neutron impulses of $q$ was distributed within $0.03 \mathrm{~nm}^{-1}$ and $0.8 \mathrm{~nm}^{-1}$. The neutrons dispersed on samples in the range of angles of $-2^{\circ} \leq \theta \leq+2^{\circ}$.

Centers (sources) of dispersion in the considered experimental range of transferred neutron impulses are nanosized non-uniformities of sample material density, that are coherent to wavelength of scattered neutrons.

Such centers in the considered samples of cement compositions are borders of various phases, grains, volume pores and pores on borders of phases or grains.

The composition of the studied cement compositions is brought in table 2 . The neutrons dispersion sections of $\sigma(q)$ brought to volume unit of a sample and a single body space angle arose from experimental ranges of SANS. The background and transmission (a passing contribution through a bunch sample without dispersion) were considered. Data were normalized in relation to neutrons dispersion intensity by a standard sample $(1 \mathrm{~mm}$ of $\mathrm{H}_{2} \mathrm{O}$ ). Figure 1 represents the experimental ranges of SANS received for cement compositions samples. Sample 2 is the hydrated Portland cement with addition of 5\% carbonate slime. Sample 3 differs from previous sample where $0.2 \%$ of surfactant is added. 


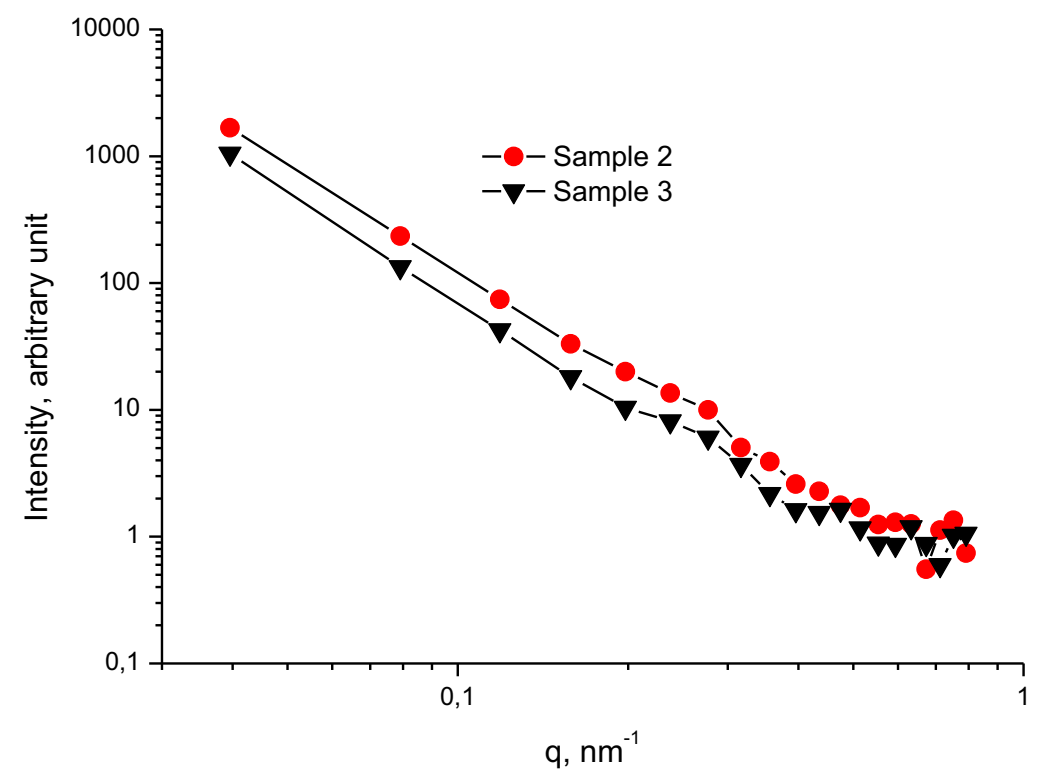

Fig. 1. Experimental ranges of SANS of cement compositions samples.

The characteristics of the studied Portland cement compositions samples, the calculated values of fractal dimension of $D$, the average size of particles $R_{c}$ for the hydrated cement compositions samples containing modifying additives are represented in Table 2.

Table 2. Structural parameters of samples in Portland cement compositions.

\begin{tabular}{|c|c|c|c|c|c|c|}
\hline Sample & $\begin{array}{c}\text { Additive type } \\
\text { (slime)/[\%] }\end{array}$ & $\begin{array}{c}\text { Surfactant } \\
{[\%]}\end{array}$ & $\begin{array}{c}\text { Water cement } \\
\text { ratio }\end{array}$ & $\begin{array}{c}\boldsymbol{D}, \\
\mathbf{1} \text { day }\end{array}$ & $\begin{array}{c}\mathbf{D}, \\
\mathbf{2 8} \\
\text { days }\end{array}$ & $\begin{array}{c}\boldsymbol{R}_{\boldsymbol{c}}, \\
\mathbf{n m}\end{array}$ \\
\hline Sample 1 & - & - & 0.30 & 3.49 & 3.31 & 65 \\
\hline Sample 2 & Carbonate/5.0 & - & 0.27 & 3.40 & 3.30 & 60 \\
\hline Sample 3 & Carbonate/5.0 & 0.2 & 0.20 & 3.28 & 3.21 & 45 \\
\hline Sample 4 & Carbonate/3.0 & - & 0.30 & 3.42 & 3.30 & 58 \\
\hline Sample 5 & Carbonate/3.0 & 0.2 & 0.22 & 3.30 & 3.24 & 44 \\
\hline Sample 6 & $\begin{array}{c}\text { Aluminum } \\
\text { alkaline/4.5 }\end{array}$ & - & 0.27 & 3.36 & 3.20 & 50 \\
\hline Sample 7 & $\begin{array}{c}\text { Aluminum } \\
\text { alkaline/4.5 }\end{array}$ & 0.2 & 0.20 & 3.25 & 3.18 & 40 \\
\hline Sample 8 & $\begin{array}{c}\text { Aluminum } \\
\text { alkaline/3.0 }\end{array}$ & - & 0.30 & 3.38 & 3.22 & 52 \\
\hline Sample 9 & $\begin{array}{c}\text { Aluminum } \\
\text { alkaline/3.0 }\end{array}$ & 0.2 & 0.22 & 3.29 & 3.19 & 40 \\
\hline
\end{tabular}

In the table 2 pairs of samples 2 and 3, 4 and 5, 6 and 7, 8 and 9 had the identical chemical composition of added slimes. The average size of particles Rc was calculated for the 28th day after a gauging of cement compositions. The softener of the S-3 brand was applied as a surfactant. 


\section{Discussion}

The use of modifying nanoadditives of technogenic origin (carbonate and the aluminum alkaline slimes) allows to influence directly on the process of hydration and formation of structural parameters of the hydrated Portland cement compositions and as a result on cement stone properties. Nanoadditives influence structural parameters of the hydrated Portland cement compositions concerning nanoparticles distribution by sizes, the average size of nanoparticles and fractal dimension. The studied cement compositions are formed by fractal clusters.

The obtained values of structural parameters of cement compositions show that slimes used as additives promote the increase in durability of contact zone particles as well as the increase water and corrosion resistance of cement stone. Directed change of structural parameters of cement compositions by adding surfactants is caused by the adsorptive modifying mechanism of dispersive systems.

\section{References}

1. S.F. Korenkova, Y.V. Sidorenko, A.M. Guryanov, European Journal of Natural History 2, 34-36 (2012)

2. A.M. Guryanov, Traditions and innovations in construction and architecture. Construction technologies (SGASU, Samara, 2015)

3. S.F. Korenkova, Yu.V. Sidorenko, A.M. Guryanov, Scientific review 6, 61-63 (2014)

4. S.F. Korenkova, Yu.V. Sidorenko, A.M. Guryanov, International journal of experimental education 6, 102-103 (2012)

5. A.M. Guryanov, Industrial and civil engineering 6, 72-75 (2015)

6. S.F. Korenkova, A.M. Guryanov, Yu.V. Sidorenko, Dry construction mixtures 3, 17-19 (2012)

7. S.F. Korenkova, A.M. Guryanov, Yu.V. Sidorenko, Traditions and innovations in a construction and architecture (SGASU, Samara, 2013)

8. S.F. Korenkova, Yu. V. Sidorenko, A. M. Guryanov, Traditions and innovations in a construction and architecture (SGASU, Samara, 2014)

9. A.M. Guryanov, Procedia Engineering 111, 283-289 (2015)

10. A.M. Guryanov, Procedia Engineering 153, 217-222 (2016)

11. S.F. Korenkova, T.V. Sheina, Foundations and concept of chemical seweage sedimentation utilization in industry (SGASU, Samara, 2004)

12. D.I. Svergun, L.A. Feygin, X-ray and neutron small angle scattering (Science, Moscow, 1986)

13. P.V. Konarev, M.V. Petoukhov, V.V. Volkov, D.I. Svergun, J. Appl. Cryst. 39, 277$286(2006)$

14. A. M. Guryanov, S.F. Korenkova, V.M. Lebedev, V.T. Lebedev, Yu.V. Sidorenko, Traditions and innovations in construction and architecture (SGASU, Samara, 2014)

15. A.M. Guryanov, S.F. Korenkova, V.M. Lebedev, V.T. Lebedev, Yu.V. Sidorenko, Traditions and innovations in construction and architecture (SGASU, Samara, 2013)

16. A.M. Guryanov, S.F. Korenkova, Yu.V. Sidorenko, V.T. Lebedev, V.M. Lebedev, Traditions and innovations in construction and architecture. Natural sciences and technosphere safety (SGASU, Samara, 2015) 